\title{
The Effect of Hygrothermal Fatigue on Physical/ Mechanical Properties and Morphology of Neat Epoxy Resin and Graphite/Epoxy Composite
}

\author{
JOVAN MIJOVIĆ* and KING-FU LIN, Chemical Engineering \\ Department, Polytechnic Institute of New York, 333 Jay Street, Brooklyn, \\ New York 11201
}

\begin{abstract}
Synopsis
The effect of moisture absorption, desorption, and thermal spiking on the physical/mechanical properties of TGDDM/DDS epoxy resin was investigated and compared to the Gr/ Ep composite. The mechanism of moisture diffusion in the neat resin was described on the morphological level. The diffusion rate of moisture in epoxy resin was found to depend on the mobility of molecular chains within an inhomogeneous epoxy network. Two well-known concepts of plasticization of amorphous polymers, the lubricity theory and the gel theory, were invoked to describe the interactions between the absorbed moisture and the resin network. Slight permanent changes in properties of the neat resin were observed after one absorptiondesorption cycle. In the thermal spiking experiment, only the spiking temperature above the glass transition of the moisture saturated epoxy resins changed their internal structure and produced very small (thin) microcracks. By comparison with the neat epoxy resin, the Gr/Ep composites contain the reinforcement-matrix boundary region, characterized by the highest restrictions to molecular mobility. The absorbed moisture during the static hygrothermal fatigue cannot effectively plasticize this region. But during thermal spiking, the formation of microcracks is observed within the reinforcement-matrix boundary region as well as an increase in the moisture content.
\end{abstract}

\section{INTRODUCTION}

Epoxies are utilized by the aerospace industry primarily in the form of matrices for composite materials and as adhesives. A number of laboratory and field studies have indicated that the absorbed moisture under the service conditions can cause significant changes in the mechanical properties of these materials. Because the exact duplication of actual service conditions in the hygrothermal fatigue testing requires impractically long times, accelerated testing methods are commonly used. In general, the exposure of samples to an aggressive environment assumes the form of either static or cyclic hygrothermal fatigue. The former is defined by the conditions of preset constant temperature and relative humidity, whereas the latter involves an application of various cyclic patterns as a function of time.

A hygrothermal fatigue treatment involves diffusion of moisture in (absorption) and/or out (desorption) of the sample. A thorough literature survey indicates that, for most neat as well as the graphite fiber-reinforced epoxy

* To whom correspondence should be addressed. 
resins, the rate of moisture diffusion is adequately described by the Fick's second law of diffusion or Fick's law with a constant diffusion coefficient. ${ }^{1-4}$

The absorbed moisture plasticizes the epoxy resin with a resultant depression in the glass transition temperature. Several research studies ${ }^{5-7}$ have used the equations based on the free volume concept ${ }^{8}$ or classical thermodynamics ${ }^{9}$ to predict the extent of plasticization of neat and reinforced epoxy resins. However, it has been pointed out that these predictions are questionable, ${ }^{10,11}$ or only qualitatively applicable, with the condition that the higher the crosslink density, the more accurate the equation. ${ }^{7}$ Nonetheless, no report in the literature contains a description of the diffusion mechanism of moisture on the morphological level and its effect on the thermomechanical properties of neat and reinforced epoxy resins. The difficulties in obtaining that information have arisen primarily from (1) the lack of understanding of the morphology of neat epoxy resin and (2) complex characteristics of the reinforcement-matrix boundary region.

Commercial $\mathrm{Gr} / \mathrm{Ep}$ composites contain over $60 \%$ by volume of graphite fiber and thus contain a large fiber surface area in contact with the epoxy matrix. Hence, two morphological regions in composites must be elucidated: (1) the bulk resin matrix and (2) the reinforcement-matrix boundary region. It was reported ${ }^{12-14}$ that the mobility of molecular chains in the reinforcement-matrix boundary region is reduced due to the adhesion force between the epoxy matrix and the reinforcing material. In addition, the molecular chains in the reinforcement-matrix boundary region experience high residual stresses, caused primarily by the mismatch in the thermal expansion coefficients between the epoxy matrix and graphite fibers. As a result, the hygrothermal fatigue-induced changes in graphite/epoxy composites are strongly affected by the character of the reinforcement-matrix boundary region.

The main objective of this study is to describe the mechanism of moisture diffusion on the morphological level using the concept of interactions between the plasticizer and the epoxy network. Then, the hygrothermal fatigue-induced changes in the physical/mechanical properties of neat and fiber-reinforced epoxy resins will be correlated to their morphology.

\section{EXPERIMENTAL}

\section{Sample Preparation}

\section{TGDDM-DDS Epoxy System}

The epoxy resin used in this study was Ciba-Geigy's MY720 resin, which contains primarily tetraglycidyl 4,4'-diaminodiphenyl methane (TGDDM) molecules. HT976 hardener, which contains primarily 4,4'-diaminodiphenyl sulfone (DDS) way added to cure the epoxy resin. A master batch of MY720 was heated to $140^{\circ} \mathrm{C}$, and the hardener was then added while stirring continuously. The mixture was then degassed in a vacuum chanber, reheated to $140^{\circ} \mathrm{C}$, and then poured into rectangular-shaped molds made from silicone rubber. The specimens were cured according to the following schedule: 3 $\mathrm{h} / 90^{\circ} \mathrm{C}+10 \mathrm{~h} / 140^{\circ} \mathrm{C}+3.5 \mathrm{~h} / 200^{\circ} \mathrm{C}$. Cured specimens had the following 
dimensions: $30 \times 10.7 \times 0.8 \mathrm{~mm}$ for dynamic mechanical testing; $100 \times$ $80 \times 1.8 \mathrm{~mm}$ for the dimensional stability testing.

Immediately after post-cure, samples were placed in a desiccator (dry/ $90^{\circ} \mathrm{C}$ ) and maintained there for 2 weeks. This step was intended to decouple the effect of physical aging (which was pronounced within the first week) and hence to establish a common baseline for all samples.

\section{Eight-Ply Unidirectional Graphite/Epoxy (AS4/3502) Composite}

All composite specimens investigated in this study were cut from the same batch of an eight-ply unidirectional graphite/epoxy (AS4/3502) composite. Cure of this material is typically done according to the schedule shown in Table I. In addition, a post-cure at $400^{\circ} \mathrm{F}\left(204^{\circ} \mathrm{C}\right)$ for $4 \mathrm{~h}$ was applied.

Samples for dynamic mechanical analysis had the following dimensions: $30 \times 11 \times 1.2 \mathrm{~mm}$. Sample edges were lightly polished in order to remove occasional surface irregularities. All samples were maintained at room temperature for 30 days prior to the initiation of experiments. The specimens were then dried to a constant weight in a desiccator at $90^{\circ} \mathrm{C}$.

\section{Testing Procedure}

Absorption was studied at $90^{\circ} \mathrm{C} / 100 \% \mathrm{RH}$ and desorption was evaluated at $90^{\circ} \mathrm{C} /$ dry atmosphere. The thermal spiking of the neat resin was carried out by exposing the moisture saturated samples to either $160^{\circ} \mathrm{C}$ or $200^{\circ} \mathrm{C}$ for $10 \mathrm{~min}$ and then quenching them to $-80^{\circ} \mathrm{C}(10 \mathrm{~min})$. The specimens were then returned to the $90^{\circ} \mathrm{C} / 100 \% \mathrm{RH}$ environment and kept there for 1 week (to resaturate them with moisture). The specimens which have completed the above described thermal spiking cycle once are referred to as once-spiked.

Dynamic mechanical measurements were performed in the DuPont 981 DMA connected to the 1090 Thermal Analyzer. Tests were run at a heating rate of $10^{\circ} \mathrm{C} / \mathrm{min}$ and at an oscillation amplitude of $0.2 \mathrm{~mm}$ peak-to-peak. Thermogravimetric analysis was performed in the DuPont 951 Model TGA connected to the 1090 Thermal Analyzer. Tests were run either at a heating rate of $10^{\circ} \mathrm{C} / \mathrm{min}$ or under chosen isothermal conditions.

One-stage carbon platinum $(\mathrm{C}-\mathrm{Pt})$ replicas of fracture surfaces of dry epoxy resin were made in a CVC evaporator at pressure of less than $5 \times$ $10^{-5}$ torr. The replica preparation procedure was described in the litera-

TABLE I

Cure Schedule of $\mathrm{Gr} / \mathrm{Ep}$ Composites

\footnotetext{
1. Pull 20 in. (508 $\mathrm{mm})$ minimum vacuum on part

2. Raise temperature to $275^{\circ} \mathrm{F}\left(135^{\circ} \mathrm{C}\right)$ at $3-5^{\circ} \mathrm{F} / \mathrm{min}\left(2-3^{\circ} \mathrm{C} / \mathrm{min}\right)$

3. Hold for $15 \mathrm{~min}$ at $275^{\circ} \mathrm{F}\left(135^{\circ} \mathrm{C}\right)$ under vacuum pressure only

4. Pressurize autoclave to $85 \mathrm{psi}(586 \mathrm{KPa})$

5. Hold at $275^{\circ} \mathrm{F}\left(135^{\circ} \mathrm{C}\right), 85 \mathrm{psi}(586 \mathrm{Kpa})$, and vacuum on the part for $45 \mathrm{~min}$

6. Raise temperature to $350^{\circ} \mathrm{F}\left(177^{\circ} \mathrm{C}\right)$ at $3-5^{\circ} \mathrm{F} / \mathrm{min}\left(2-3^{\circ} \mathrm{C} / \mathrm{min}\right)$

7. Hold for $2 \mathrm{~h}$

8. Cool part to $150^{\circ} \mathrm{F}\left(66^{\circ} \mathrm{C}\right)$ in not less than $45 \mathrm{~min}$. Maintain pressure and vacuum

9. Remove from autoclave
} 
ture. ${ }^{15}$ A JEM-120 transmission electron microscope was used to investigate the fracture surface morphology. Scanning electron microscopy was also performed on the fracture surfaces of dry and thermally spiked epoxy resins. The fracture surfaces of specimens were gold shadowed and an AMR-1200 scanning electron microscope was used to investigate the surfaces.

\section{RESULTS AND DISCUSSION}

\section{Dry Condition}

The primary goal of this study was to describe the interactions between the absorbed moisture and the epoxy network. The transport of moisture through the epoxy network involves cooperative motion of water molecules and the 3-dimensional resin network. But before the effect of moisture absorption, desorption, and thermal spiking on the physical/mechanical properties of neat TGDDM/DDS epoxy resin is studied and compared with the Gr/Ep composite, it is imperative to describe molecular motions in dry samples. For that purpose, dynamic mechanical analysis was used as a method which provides the most sensitive response of solid polymers to various transitions, relaxations, and morphological inhomogeneities over a wide temperature range.

By measuring the dynamic mechanical properties of the neat resin in dry condition, we have established a baseline for the subsequent study of hygrothermal fatigue. Dynamic mechanical spectrum of a dry epoxy resin is shown in Figure 1. Two large peaks are seen in the loss modulus curve shown in this figure. The $\alpha$ peak represents the glass transition, which is hereafter defined by the location of the loss modulus ( $\alpha$ peak) in the dynamic mechanical spectrum $\left(T_{g}=250^{\circ} \mathrm{C}\right.$ in Fig. 1). Below the glass transition temperature, there is no large scale motion within the network. However,

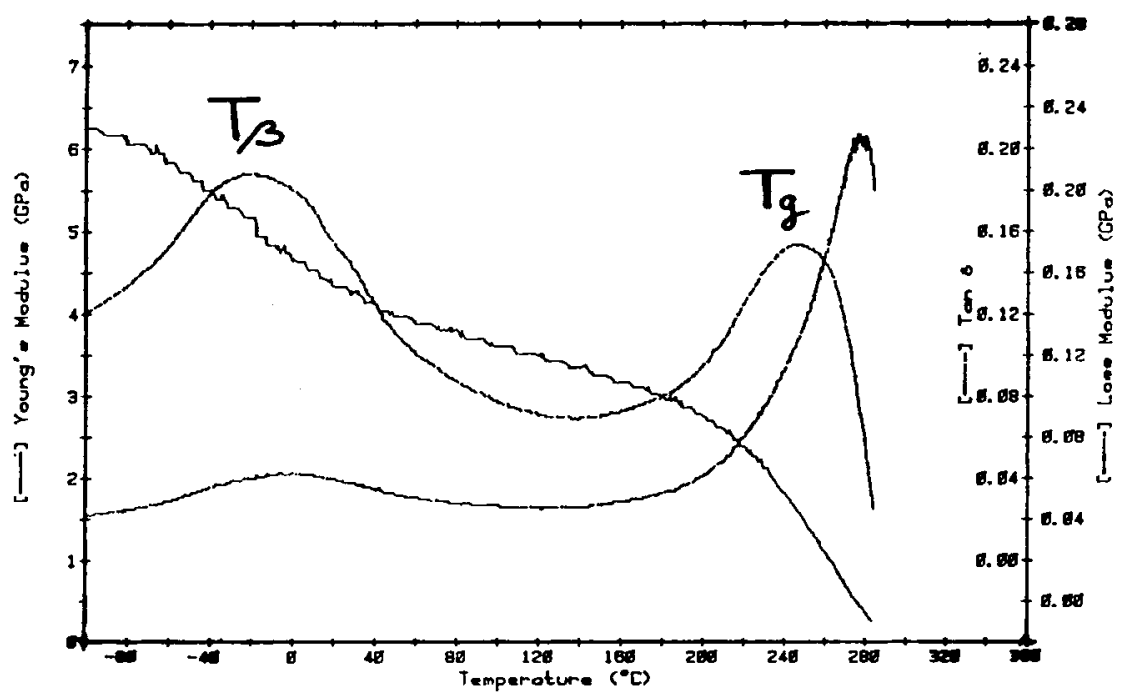

Fig. 1. Dynamic mechanical spectrum of an untreated, dry TGDDM/DDS epoxy resin. 
a big and broad $\beta$ transition, with a peak value at $-20^{\circ} \mathrm{C}$, is also observed and is related to the relaxation of the local chain segments in the crosslinked structure. But, due to the lack of complete understanding of the glassy structure of epoxy resins and the limitations of dynamic mechanical tests, the exact molecular origin of the low temperature relaxation in epoxy resins has been a controversial subject over the past two decades. Several mechanisms have been put forward to explain this low temperature relaxation phenomenon, such as the crankshaft motion of glyceryl groups, ${ }^{16-18}$ wagging of the phenyl groups, ${ }^{19}$ and intermolecular bond loosing. ${ }^{20}$ Williams ${ }^{21}$ suggested that the $\beta$ transition peak has at least two basic components. One is related to the presence of glyceryl units derived from polyfunctional glycidyl compounds, while the other may be related to the presence of diphenylpropane units in the resin. However, Takahama and Geil ${ }^{22}$ disagreed with the proposed contribution of diphenylpropane group to the $\beta$ relaxation. They claimed that the diphenylpropane motion occurs near $-110^{\circ} \mathrm{C}$, far below the typical $\beta$ transition range. A recent study of a series of bifunctional epoxies cured with aliphatic and aromatic amines concluded that the origin of the $\beta$ relaxation is in the motion of segments containing nitrogen, three carbons, and an oxygen atom. ${ }^{23}$

Although some uncertainty over the exact molecular origin of $\beta$ transition remains, it is generally accepted that the $\beta$ transition is markedly dependent on the degree of cure and the curing agent concentration. ${ }^{16,23-25}$ The $\beta$ peak intensity increases, and the peak temperature shifts to higher temperature as both the degree of cure and the curing agent concentration are increased. This experimental observation has been, in most cases, ascribed to the increased concentration of glyceryl groups during cure. Moreover, Arridge and Speake ${ }^{24}$ pointed out that the mobility of the glyceryl groups is restricted and possibly hindered by the surrounding crosslinked network. Hence, the $\beta$ transition temperature can be influenced by the crosslinking density. Ochi et al ${ }^{26}$ argued that the $\beta$ relaxation of the cured epoxy resins containing glyceryl groups represents a sum of contributions from the relaxation of these groups and the other parts of the network structure. Takahama and Geil ${ }^{(22)}$ found that the transition temperature of the crosslinked epoxy resin was higher than that of linear phenoxy resin, based on the same concentration of glyceryl groups. They suggested that the motion of crosslinks themselves may contribute to the higher $\beta$ transition temperature of the cured epoxy resin. Based upon the published information and our own results, a schematic representation of the effect of crosslinking on $\beta$ relaxation is shown in Figure 2. It is seen in this figure that the glyceryl groups attached to the crosslinked points [Fig. 2(a)] experience a higher restriction to local chain motion than those in the main chain [Fig. 2(b)]. The hindrance to local motion of glyceryl group imposed by the crosslinked points should not be overlooked in the study of the mechanism of $\beta$ transition. It follows, then, that the change in the environment around the glyceryl portions should influence the $\beta$ relaxation. In other words, either a change in morphology (e.g., increase in crosslinked density-see Fig. 2) or the addition of an external species (which can either retard or facilitate the local motion of chain segments) is likely to affect the $\beta$ relaxation.

It is worth mentioning here that in dynamic mechanical measurements 


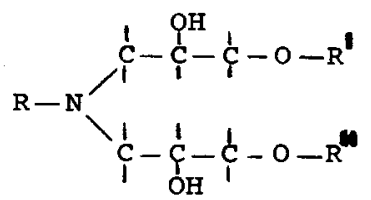

(a)

$$
\begin{aligned}
& R-0-\frac{1}{C}-\frac{p^{H}}{c}-\frac{1}{c}-0-R^{\prime} \\
& R-\underset{1}{N}-\underset{1}{C}-\stackrel{1}{C}-\stackrel{1}{C}-O-R^{m}
\end{aligned}
$$

Fig. 2. Schematic of various types of glyceryl portions present in epoxy networks.

of $\beta$ relaxation, the dynamic stress (or strain) is applied onto a glassy structure, and thus the interpretation of the results without prior consideration of the structural factors and/or morphology is dangerous. For example, if the epoxy resin is not homogeneous, the weaker part in the structure is likely to preferentially deform and relax during the dynamic mechanical test. Thus, the morphology of the cured epoxy resin should be investigated first. We have employed transmission electron microscopy (TEM) to study the epoxy morphology. Figure 3 shows a transmission electron micrograph (TEM) of a fracture surface replica of dry TGDDM/DDS epoxy resin. An inhomogeneous morphology, in which the highly crosslinked regions are dispersed in the lower crosslink density matrix, has been observed in various epoxy resins, ${ }^{27}$ and is also apparent here. Let us now assume that the difference in crosslinking density between the more highly crosslinked regions and the lower crosslink density matrix exists to the

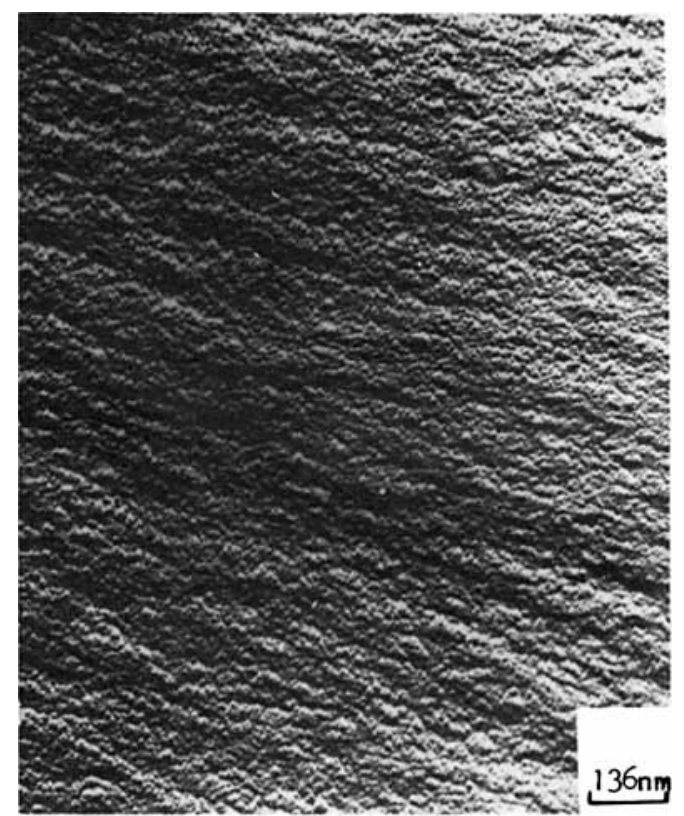

Fig. 3. Transmission electron micrograph of a fracture surface replica of dry TGDDM/ DDS epoxy resin. Magnification 73,000 $\times$. Note the inhomogeneous structure of the fracture surface. 
point that the highly crosslinked regions can be regarded as solid spheres (idealization), connected by the more flexible molecular chains in the lower crosslink density matrix. The deformation and relaxation in the glassy structure, caused by the external dynamic stress, will then be dominated by the lower crosslink density matrix. This postulate is consistent with a previous study, ${ }^{25}$ which indicated that the elastic storage modulus in the glassy state was determined primarily by the lower crosslink density matrix. Although the relaxation of glyceryl groups occurs throughout the entire network in the $\beta$-transition range, the relaxations in the lower crosslink density regions would contribute more to the overall $\beta$ relaxations observed in the dynamic mechanical spectra.

Several interesting questions have arisen in connection with the extension of the above concept to composites. Can one learn about the properties of composites from the properties of neat resins? Can the argument that the weaker part in the glassy structure is easier to deform and relax during the application of an external dynamic stress be extended to the composites? In the studies of composites, an additional difficulty arises from the presence of the reinforcement-matrix boundary region. This is a region (not a "phase") which extends from the outer layer of the reinforcement to some distance into the thermoset matrix, and whose characteristics depend on factors such as the morphology and surface energy of the fiber skin, the type of the fiber surface treatment and its interactions with the fiber and the matrix, the difference in the coefficients of thermal expansion of fibers and matrix, the state of residual stresses, and the morphological gradient in the matrix. The most prominent aspect of significance of this boundary region is its response to an aggressive environment and its role in determination of long-term performance of composites. Beaumont and $\mathrm{Harris}^{28}$ pointed out that the fracture energy of the unidirectional reinforced composite in a brittle resin matrix is dependent principally on the frictional shear stress in the reinforcement-matrix boundary regions and determined by the interfacial shear strength and the void content. Besides, Ashbee and Wyatt ${ }^{29}$ found that moisture may act to break the bonds between the fiber and the matrix, resulting in a permanently altered interfacial strength. Kaelble et al.$^{30}$ also postulate a reduction in the interfacial strength of graphite/epoxy composite when moisture is absorbed. It is generally recognized $^{31}$ that the reinforcement-matrix boundary region is the determining factor in the reinforcing mechanism, especially with regards to the wet strength retention. Williams ${ }^{32}$ found that the change in $\beta$ transition of the epoxy composite during moisture absorption was highly dependent on the moisture content absorbed in the reinforcement-matrix boundary regions. According to the existing experimental evidence, it appears that the weaker part in the structure of composites in wet condition is the reinforcement-matrix boundary region which is easier to deform and relax during the application of an external dynamic stress and hence contributes more to the overall $\beta$ relaxations.

Bearing in mind the concept of dynamic mechanical behavior of neat and reinforced epoxy resins, we now turn our attention to the mechanism of moisture absorption in epoxy resins on the molecular level. 


\section{Absorption}

When the neat epoxy resin was exposed to the aggressive environment at $90^{\circ} \mathrm{C}$ and $100 \% \mathrm{RH}$, an increase in the moisture content (weight gain) as a function of time was observed, as shown in Figure 4. The moisture content, a parameter of practical interest, was calculated from the following equation:

$$
M=\frac{M_{w}-M_{d}}{M_{d}} \times 100 \%
$$

where $M_{w}$ is the weight of moist sample and $M_{d}$ the weight of dry sample. The apparent diffusivity $(D)$ can be experimentally determined from the initial (linear) portion of the weight vs. square root of time curve. A value of $D=1.36 \times 10^{-6} \mathrm{~mm}^{2} / \mathrm{s}$ was calculated from Figure 4 . The solution to Fick's second law with the corresponding set of boundary conditions for three-dimensional diffusion into a rectangular plate has been given. ${ }^{3}$ The final form of that solution, utilized in our study, is given by

$$
\begin{aligned}
& G=\frac{M_{t}-M_{0}}{M_{\infty}-M_{0}}=1-\frac{8}{\pi^{2}}\left\{1-\frac{\sqrt{D t}}{\sqrt{\pi l^{2}}}\left(1-4 \frac{\sqrt{D t}}{\sqrt{\pi n^{2}}}\right) \sum_{i}^{\infty} \frac{1}{\sum_{0}(2 i+1)^{2}}\right. \\
& \left.\exp \left[-(2 i+1)^{2} \frac{\pi^{2} D t}{h^{2}}\right]\right)
\end{aligned}
$$

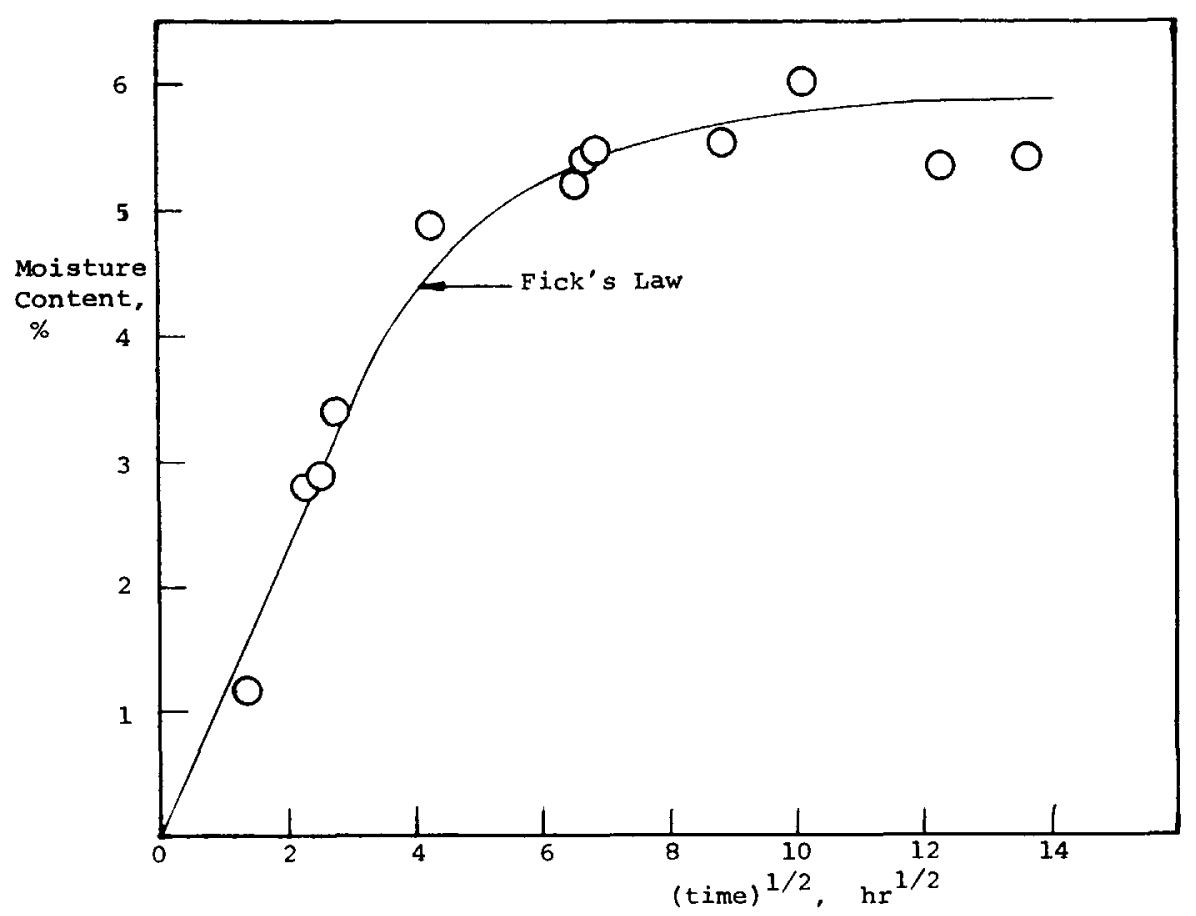

Fig. 4. Moisture content of neat epoxy resin as a function of square root of time of exposure to $90^{\circ} \mathrm{C} / 100 \% \mathrm{RH}$. 
where $M_{0}, M_{\infty}$, and $M_{t}$ are the weight of specimen at moisture absorption time equal to zero, infinity, and $t$ and $l, n$, and $h$ are the specimen length, width, and thickness, respectively. A good agreement between the Fick's second law [eq. (2)] and the experimental data was obtained, as seen in Figure 4.

Changes in dynamic mechanical properties of the neat epoxy resin during moisture absorption were also monitored in order to evaluate the mechanism of moisture diffusion on the morphological level. Figure 5 shows the plot of the $\beta$ transition peak temperature as a function of moisture content. As seen in this figure, $\beta$ transition decreases rapidly to lower temperature during the initial stage of moisture absorption and then continues to decrease but at a slower rate. Finally, the $\beta$ transition temperature peak reaches $-72^{\circ} \mathrm{C}$. At that point the specimen is saturated with moisture. Simultaneous changes in $T_{g}$ ( $\alpha$ peak) as a function of moisture content are described in Figure 6. Apparently, the $T_{g}$ of the neat epoxy resin, unlike the $T_{\beta}$, does not change much in the initial stage of moisture absorption, until the moisture content of about $2.5 \%$ is reached. Then, the glass transition temperature begins to decrease sharply and finally reaches the temperature of $180^{\circ} \mathrm{C}$ (corresponding to the moisture saturated specimen). The following correlation was established between the glass transition $\left(T_{g}\right)$ and the moisture content $(M)$ :

$$
T_{g}=248.4+1.6 M-0.3 M^{2}-0.8 M^{3}+.08 M^{4}
$$

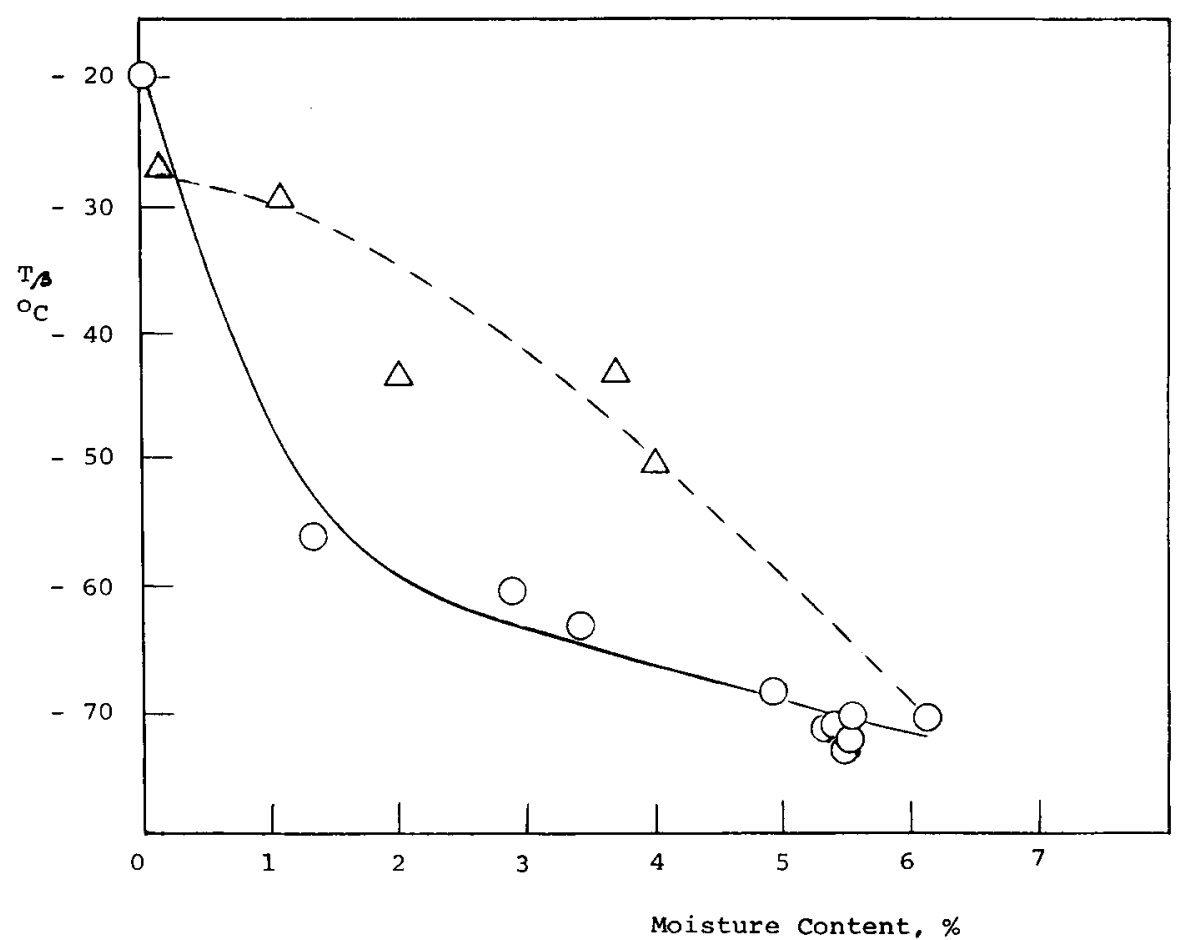

Fig. 5. $\beta$-Transition peak temperature of neat epoxy resin as a function of moisture content during absorption and desorption: $(O)$ absorption; $(\triangle)$ desorption. 


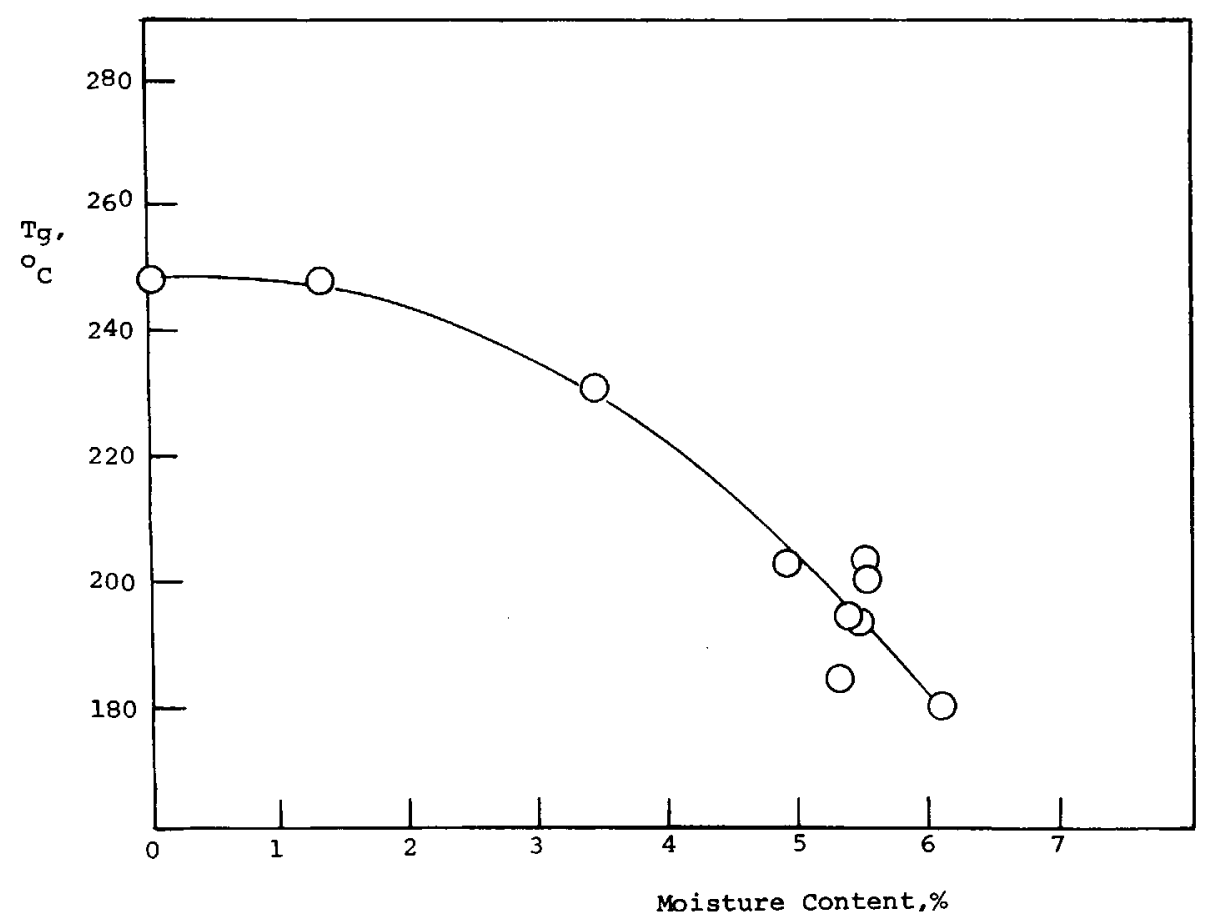

Fig. 6. Glass transition peak temperature of neat epoxy resin as a function of moisture content during absorption.

The effect of absorbed moisture on glass transition of an epoxy resin has been also studied by McKague et al., ${ }^{6}$ who reported a decrease in $T_{g}$ of more than $100^{\circ} \mathrm{C}$ upon absorption of $6-7 \%$ water. Peyser and Bascom, ${ }^{10}$ however, disagreed with such an extensive plasticization effect. They reported a $50^{\circ} \mathrm{C}$ decrease in $T_{g}$ of samples containing $7 \%$ water. Our results are in excellent agreement with their data, as clearly seen in Figure 6. Finally, Ellis and Karasz ${ }^{7}$ have recently pointed out that the depression in $T_{g}$ is a function of the crosslink density. An equation derived from the thermodynamic principles provided a qualitative agreement with the experimental results.

In order to interpret the experimental data obtained from the dynamic mechanical measurements, one must further clarify the diffusion mechanism of moisture in the epoxy resin on the molecular level and understand how the absorbed moisture interacts with the epoxy network. To aid our interpretation of the moisture-network interactions, we shall now invoke some basic concepts of plasticization of polymeric materials. Since the first half of this century, two principal theories, the lubricity theory and the gel theory, have been proposed to account for the main effects that plasticizers have on amorphous polymers. ${ }^{33}$ The lubricity theory views the plasticizer as a lubricant which facilitates movements of the chain segments of the macromolecules, even if other parts of the macromolecules "are associated in some kind of a gel network." 34 The gel theory considers the resistance of polymeric chains to deformation to result from the gel network which is formed by "more or less loose attachments that occur at intervals along the polymer chains." 35 The action of a plasticizer on the resin is to break 
those attachments and mask the centers of force that have held the polymer chains together, by selectively solvating the polymer at these points. Those two theories are not mutually exclusive, are generally accepted, and provide a qualitative concept of the interactions between plasticizers and an amorphous polymer on the molecular level. Nevertheless, the two theories have not been routinely applied to describe the plasticization of epoxy resins by abosrbed moisture. One exception is an electron microscopic study of the mechanism of interactions between the plasticizer and an epoxy resin. ${ }^{36}$ According to the interpretation of those authors, the epoxy resin has a heterogeneous morphology which can be significantly changed by introduction of plasticizer into the crosslinked network. They proceeded to describe two plasticization mechanisms as follows. The first one is intrabundle (molecular) plasticization. The plasticizer which performs intrabundle plasticization is introduced into the highly crosslinked regions, swells those regions, and decreases the glass transition temperature of the epoxy resin. The other is interbundle (structural) plasticization. The plasticizer which performs interbundle plasticization stays outside the highly crosslinked regions and has little effect on the glass transition temperature of the epoxy resin.

Let us now try to expand the concept of plasticization of heterogenous crosslinked network in an attempt to further clarify the mechanism of moisture diffusion in epoxy resins on the molecular level. The random Brownian motions of water molecules are rapid compared to those of the molecular chains in the resin network. As a result, the rate of moisture diffusion is controlled by the epoxy resin. Furthermore, assuming that the mobility of chain segments is more restricted in highly crosslinked regions than in the lower crosslink density matrix, the rate of moisture diffusion through the matrix is expected to be higher. Therefore, in the first stage of moisture absorption, water molecules are believed to penetrate into the lower crosslink density matrix region at a faster rate than into the highly crosslinked regions. One explanation for the observed rapid shift of the $\beta$ transition peak to lower temperature (Fig. 5) is that the absorbed water interacts with the glyceryl groups and facilitates their local motion. This explanation is consistent with the concept of the lubricity theory of plasticization. On the other hand, in the initial stage of moisture absorption, the $T_{g}$ of moist samples decreases only slightly (Fig. 6), supporting the hypothesis that the absorbed moisture does not enter the highly crosslinked regions to a large extent and hence cannot perform the intrabundle plasticization which was described earlier. According to the intrabundle (molecular) plasticization mechanism ${ }^{36}$ and the plasticization mechanism described by the gel theory, the plasticizer which enters the highly crosslinked structure can swell that structure and decreases the glass transition temperature.

Another way of following the changes in the epoxy network during absorption is by monitoring the moisture-induced swelling strains. Since the glass transition temperature of epoxy resin during moisture absorption does not change much until the moisture content of about $2.5 \%$ is reached (Fig. 6), one would also expect the moisture-induced swelling strain in the epoxy resin to change slowly in the initial stage of absorption. We then proceeded 
to measure the swelling strain in the epoxy resin during moisture absorption. Figure 7 shows the change in specimen length as a function of moisture content. As seen in this figure, the rate of swelling is lower during the initial moisture absorption, until approximately $2.5 \%$ of moisture content is reached. After that point, the swelling strain increases sharply. Similar swelling behavior has been observed in Narmco 5208 epoxy resin during moisture absorption at $60^{\circ} \mathrm{C}$ and $77 \% \mathrm{RH}^{6} \mathrm{Marom}^{37}$ has also reported that no swelling strains were observed in an epoxy resin immersed in boiling water until after a certain amount of water had been absorbed. In the graphite/epoxy composites, a similar induction period with respect to the swelling strain has been reported. ${ }^{22}$ In that study, a model was used to describe the swelling behavior of the composite. According to the author, the swelling was negligible (i.e., difficult to measure) during the initial moisture absorption until a certain threshold value of moisture concentration was reached. Above that value, a linear increase in swelling strain was recorded as a function of time. It is worth noting here that the observed trends in the swelling strain and the glass transition temperature as a function of moisture content are qualitatively similar. We believe that they are governed by the same mechanism, i.e., the decrease of the glass transition temperature of moist epoxy resin is related to the swelling of the highly crosslinked structure. The $2.5 \%$ moisture content can be defined as

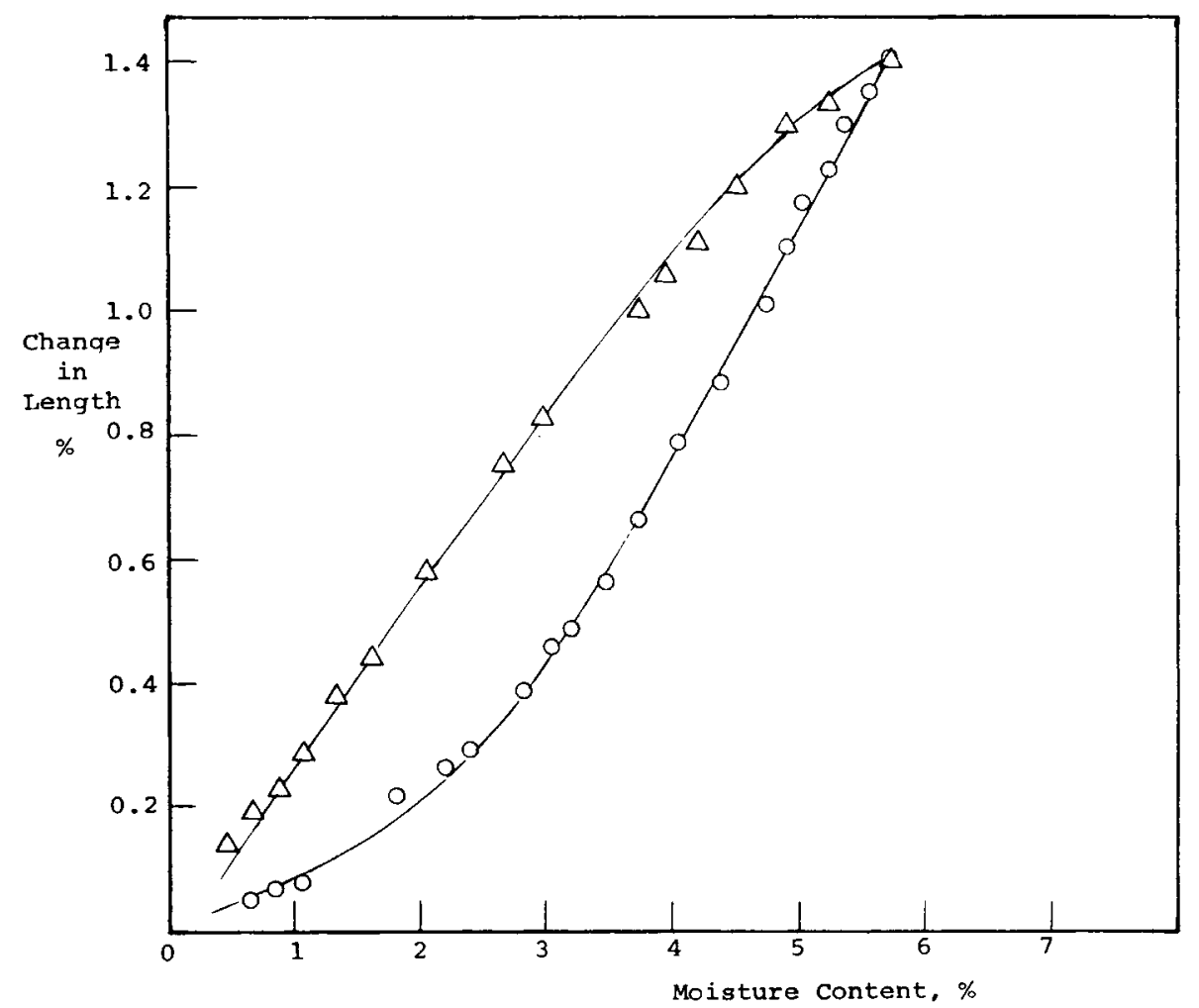

Fig. 7. Change in length of neat epoxy resin as a function of moisture content during absorption and desorption: $(O)$ absorption; $(\triangle)$ desorption. 
the threshold value of moisture content after which the moisture absorbs into the highly crosslinked regions and swells them. On the other hand, since the mobility of molecular chains in the highly crosslinked regions is restricted by the crosslink points, the absorbed moisture cannot readily facilitate the motion of the chain segments (i.e., cannot lubricate the chain segments) at low temperatures. This then explains why the $T_{\beta}$ decreases at a slower rate after the threshold value of moisture content has been reached. In samples saturated with moisture, a 5.7\% moisture content and a $1.5 \%$ change in length were measured. Figure 8 shows the dynamic mechanical spectrum of a moisture saturated epoxy resin. The $T_{g}$ peak in the loss modulus spectrum appears at $180^{\circ} \mathrm{C}$, about $70^{\circ} \mathrm{C}$ below that of the dry sample. The $T_{\beta}$ peak which has shifted from -20 to $-72^{\circ} \mathrm{C}$, also becomes broader and bigger. By a direct comparison of TGA and DMA thermograms, obtained at the same heating rate, we have also shown that the moisture lost during the test is not crucial in determining the $T_{g}$ of wet resins. At the peak value of the loss modulus trace $\left(T_{g}\right)$ of the saturated sample $(6 \%$ moisture gain), only about $1 \%$ moisture loss had been detected in a comparable TGA run.

Let us now attempt to draw a comparison between moisture absorption in the neat resin and the $\mathrm{Gr} / \mathrm{Ep}$ composites. In order to do that, dynamic mechanical spectra of dry and moisture saturated unidirectional (eight-ply) $\mathrm{Gr} / \mathrm{Ep}$ composite are shown in Figures 9 and 10, respectively. A comparison of Figures 9 and 10 reveals that the major $T_{g}$ peak in the moisture saturated composite sample appears at about $70^{\circ} \mathrm{C}$ below the glass transition temperature of the dry sample. Several additional interesting observations were made in Figures 9 and 10. Young's modulus of the moisture saturated composite (Fig. 10) changes by less than $10 \%$ over a temperature range of $200^{\circ} \mathrm{C}$ while the Young's modulus of the moisture saturated neat epoxy

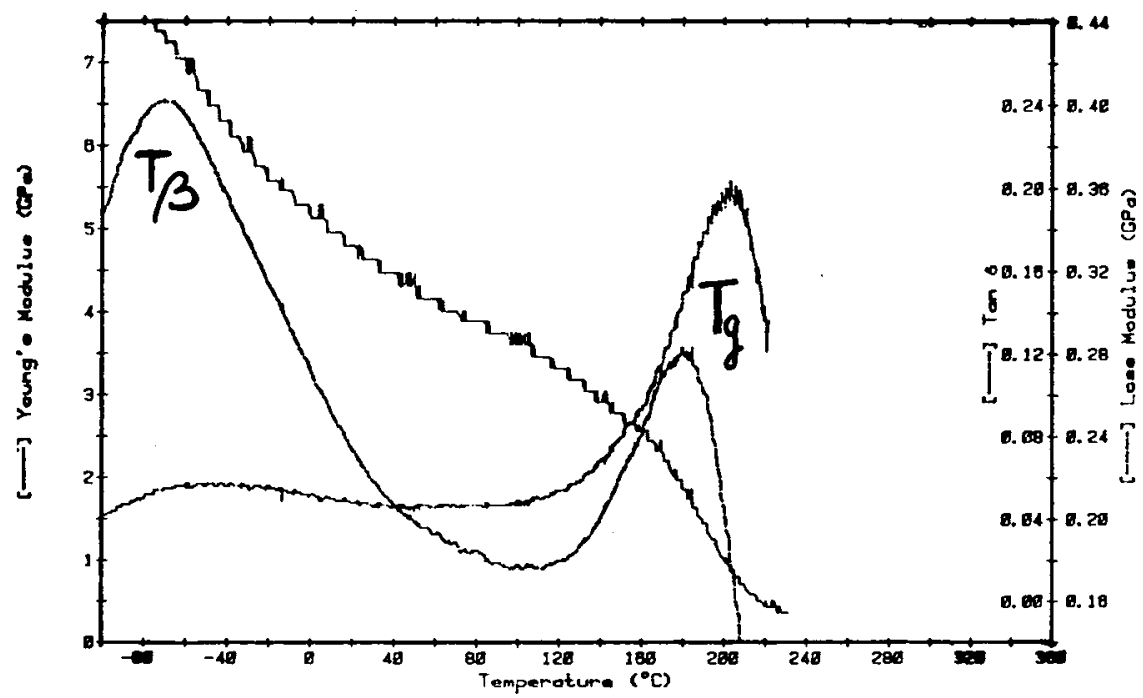

Fig. 8. Dynamic mechanical spectrum of a moisture saturated $\left(90^{\circ} \mathrm{C} / 100 \% \mathrm{RH}\right) \mathrm{TGDDM} /$ DDS epoxy resin. 


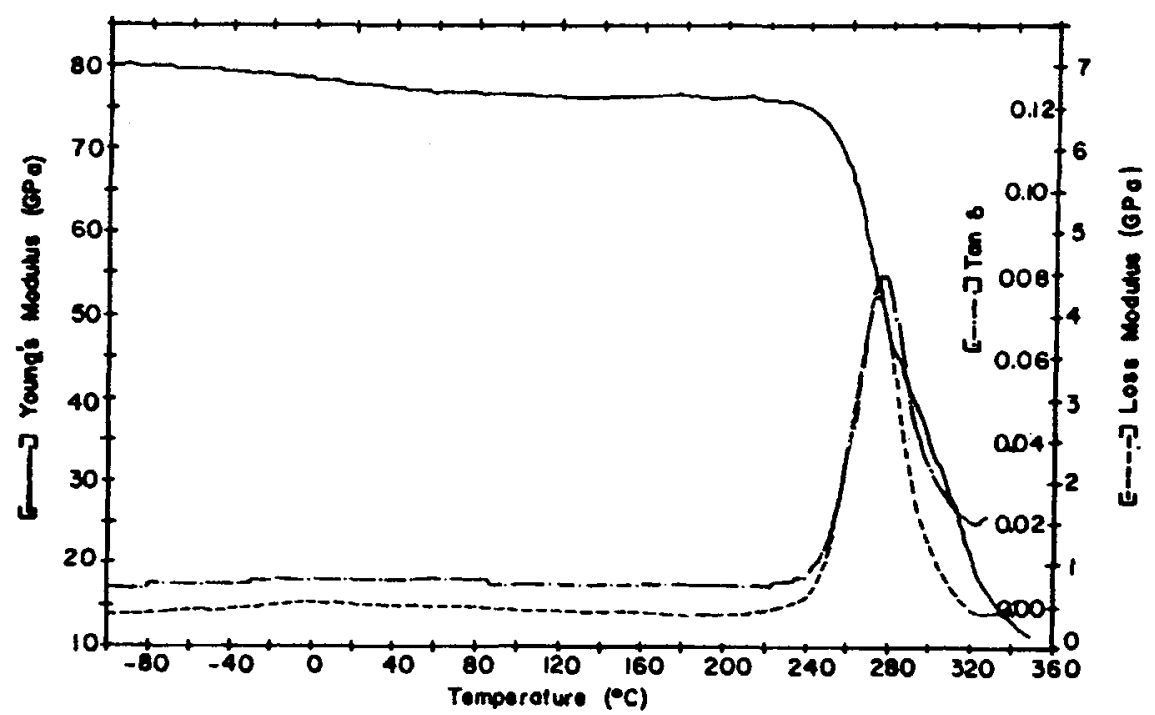

Fig. 9. Dynamic mechanical spectrum of an untreated, dry eight-ply undirectional AS/ 3502 graphite/epoxy composite.

resin (Fig. 8) changes by more then $50 \%$ over the corresponding temperature range. This difference is, at least partly, due to the fact that the epoxy composite contains over $60 \%$ graphite fibers which do not absorb moisture or undergo physical changes during testing. Young's modulus was measured in the fiber direction and as such is a fiber-dominated property in the composite. Considering the impermeability of bulk graphite fibers, the change in the thermomechanical properties of moisture saturated epoxy composite in the glass transition range are entirely influenced by two regions: (1) the bulk epoxy resin within the composite and (2) the reinforce-

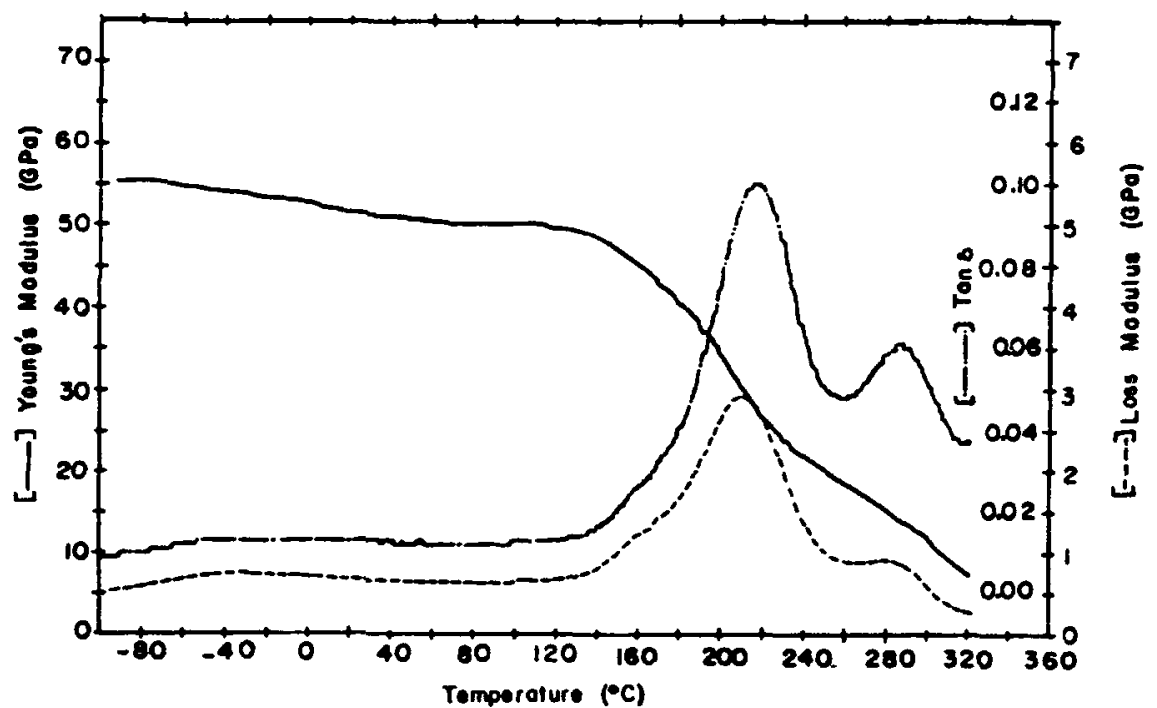

Fig. 10. Dynamic mechanical spectrum of a moisture saturated $\left(90^{\circ} \mathrm{C} / 100 \% \mathrm{RH}\right)$ eight-ply unidirectional AS/3502 graphite/epoxy composite. 
ment-matrix boundary region. A preferential penetration of absorbed moisture into the bulk resin as opposed to the resin network within the reinforcement-matrix boundary region in a composite has been reported.$^{38}$ An example of it is shown in Figure 10 which contains two peaks in the loss modulus spectrum in the glass transition range of the moisture saturated composite. The major $T_{g}$ peak located at $210^{\circ} \mathrm{C}$ represents the $T_{g}$ of the bulk resin within the composite, whereas the other smaller peak, located at $280^{\circ} \mathrm{C}$, represents the $T_{g}$ of the epoxy network within the reinforcementmatrix boundary region. ${ }^{39}$ Due to the more restricted molecular mobility within the reinforcement-matrix boundary region, the extent of moisture absorption is smaller in the boundary region than in the bulk matrix. By preferential penetration, the absorbed moisture has enlarged the difference in the local mobility of chain segments in different parts of the resin network, to the point detectable by dynamic mechanical measurements (Fig. 10). An important point here is that the very existence of this boundary region precludes the application of results obtained with a neat resin, to the same resin in the composite. In the light of the complexity of the reinforcement-matrix boundary region, one must be particularly careful when considering the theoretical predictions of mechanical behavior of composites in various environments. The main drawback of the majority of such analytical models is the assumption of the presence of a time-independent two-dimensional "interface," envisioned as an infinitely thin surface between the fibers and the matrix, across which there exists a "perfect" adhesion between the phases.

\section{Desorption}

In addition to moisture absorption, desorption was investigated in order to determine the extent of reversibility and/or permanence of the changes in physical/mechanical propertis of the neat resin. The diffusivity was determined, as in the case of absorption, from the initial linear portion of the moisture content vs. square root of desorption time curve. A value of $D=$ $2.36 \times 10^{-6} \mathrm{~mm}^{2} / \mathrm{s}$ was calculated from Figure 11. The solution of Fick's second law for desorption can be obtained by setting $M_{\infty}=0$, and $M_{0}=$ $M_{s}$ where $M_{s}$ is the moisture content of moisture saturated sample. In that case, eq. (2) takes the following form:

$$
M / M_{s}=1-G
$$

where $G$ is defined by eq. (2).

Figure 11 shows that the experimental data follow Fick's second law during the initial stage of desorption, until about $2 \%$ of moisture content is reached. The rate of desorption then slows down and begins to deviate from Fick's second law. The higher diffusion coefficient observed during moisture desorption is partly due to the release of the swelling strains formed during absorption.

Next, we focused our attention to changes in the $T_{\beta}$ and the swelling strain during desorption. Initially, the $T_{\beta}$ shifts rapidly to higher temperature (Fig. 5) while the swelling strain decreases steadily (Fig. 7). In ac- 


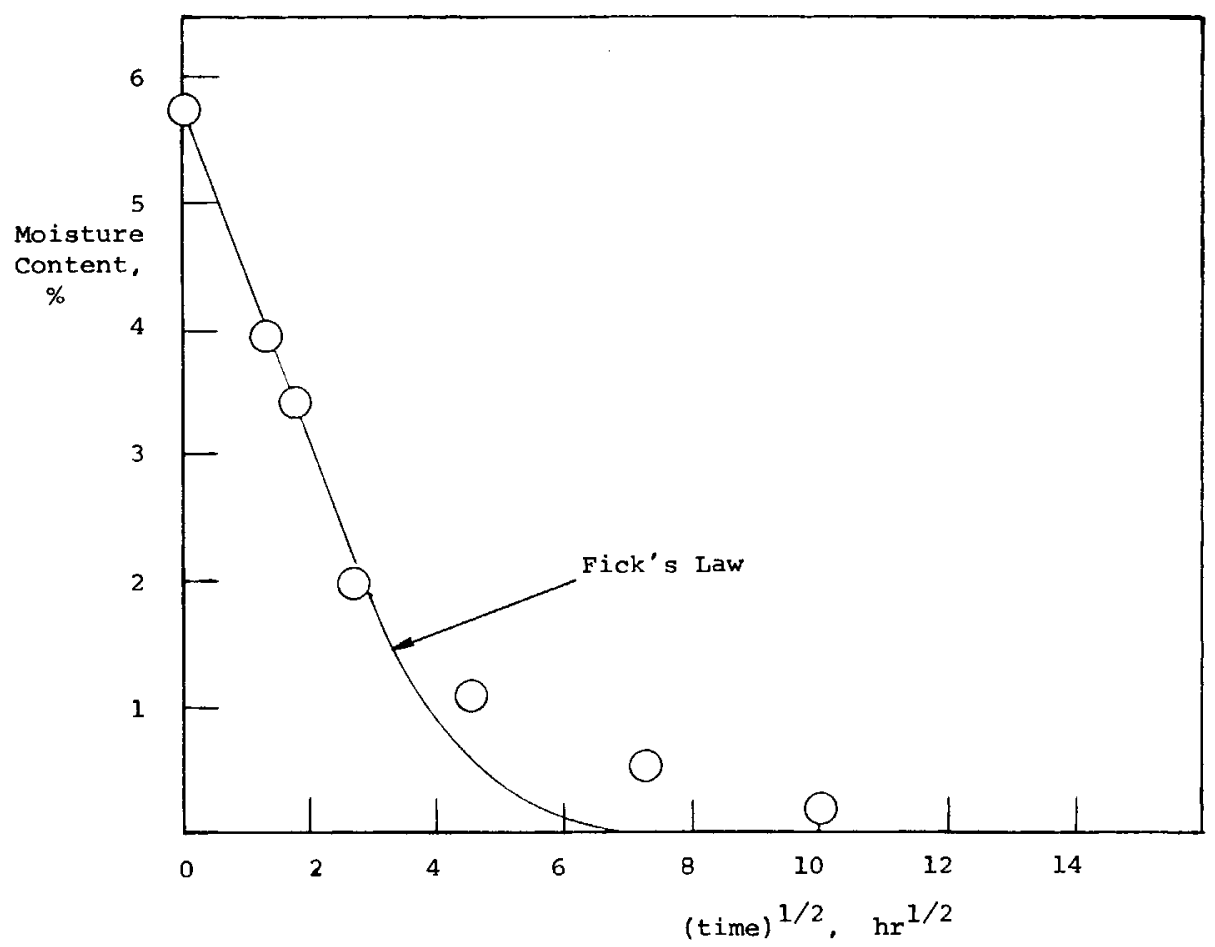

Fig. 11. Moisture content of neat epoxy resin as a function of square root of time during desorption in the dry environment $/ 90^{\circ} \mathrm{C}$.

cordance with our diffusion concept, the fast initial change in $T_{\beta}$ is an indication of preferential desorption from the lower crosslink density matrix.

A common question in every desorption study is whether one absorptiondesorption cycle produces permanent changes in the material. To check that, samples were tested at the end of the desorption cycle. Figure 12 shows a dynamic mechanical spectrum of the redried neat resin which has retained less than $0.3 \%$ of water (this specimen had been dried to a constant weight but had slightly higher dry weight than the untreated dry sample). Interestingly, although the $\beta$ transition has shifted back from -72 to $-26^{\circ} \mathrm{C}$, the glass transition separated into two peaks, $T_{g}^{\prime}$ and $T_{g}^{\prime \prime}$. One of them $\left(T_{g}^{\prime}\right)$ remained in the $T_{g}$ range of the moisture saturated epoxy resin, while the other $\left(T_{g}^{\prime \prime}\right)$ shifted back to the $T_{g}$ range of the untreated dry epoxy resin. A peak similar to $T_{g}^{\prime}$ has been reported in a Narmco 5208 epoxy resin by Peyser and Bascom. ${ }^{10}$ They related that peak to the molecular structure resulting from the decomposition of epoxy resin assisted by the absorbed water. It is possible that water, which remains in the highly crosslinked regions and where it acts as an aggressive environment for a long period of time, could slowly hydrolize the highly crosslinked network. Since the weight of the redried sample was higher than that of the untreated sample, it is possible that some water has participated in reactions within the network. One could perhaps argue that the separation of $T_{g}$ peak is the result of an increase in the amount of unattached (free end) molecular chains in the less highly crosslinked regions. That increase (due to the hydrolysis of 


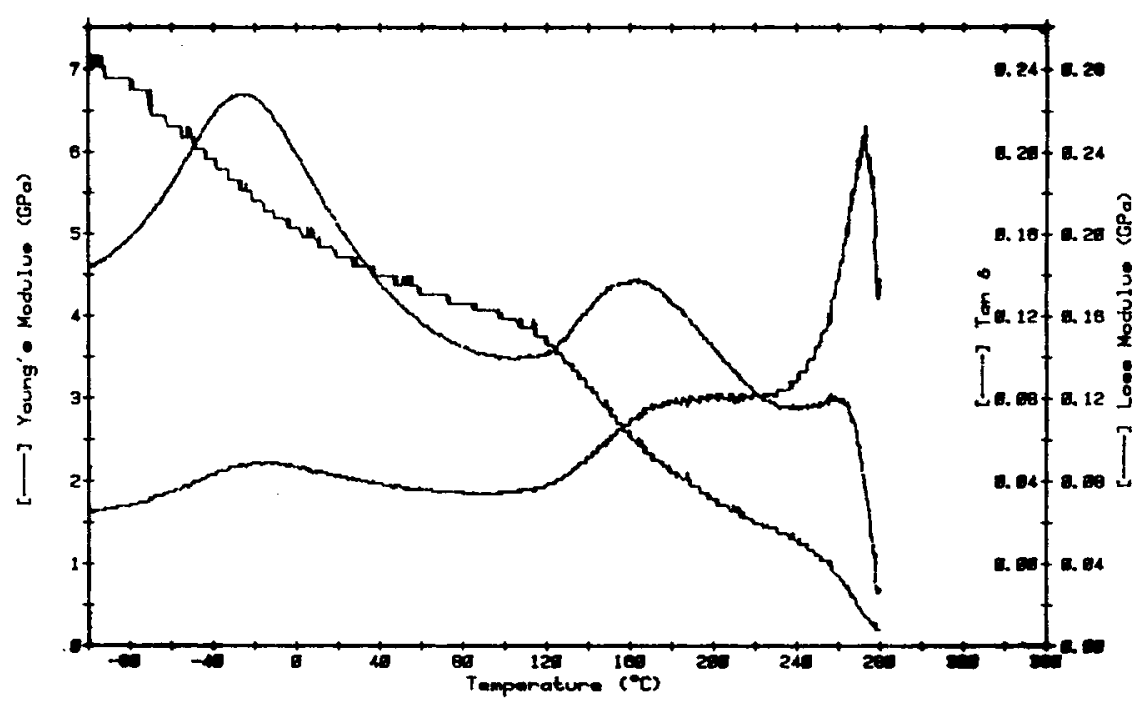

Fig. 12. Dynamic mechanical spectrum of a moisture saturated and then redried TGDDM/ DDS epoxy resin.

crosslinked points in the highly crosslinked regions) causes the matrix to respond separately. The observed $T_{g}^{\prime}$ peak would then represent the $T_{g}$ of the resin network in the lower crosslink density matrix whereas the $T_{g}^{\prime \prime}$ peak would represent the $T_{g}$ of highly crosslinked regions. The splitting of the glass transition peak was not seen in the redried $\mathrm{Gr} / \mathrm{Ep}$ composites. ${ }^{38}$ Dynamic mechanical properties of those samples (unidirectional) were measured in the fiber direction and hence are not very sensitive to subtle changes in the resin.

To gain further insight into the hygrothermal fatigue of the neat epoxy resin during one absorption-desorption cycle, a thermogravimetric analysis was performed. Our first intention was to compare the total weight loss upon high temperature degradation of: (1) the moisture saturated, (2) the moisture saturated and then dried, and (3) the untreated dry samples. The results of measurements of weight loss as a function of temperature for those three samples are shown in Figure 13. Curve 1 represents the untreated dry sample, curve 2 the moisture saturated sample, and curve 3 the moisture saturated and then dried sample. All three samples have the same degradation temperature $\left(T_{d}=380^{\circ} \mathrm{C}\right)$, which is defined as the temperature at which $15 \%$ of the initial weight has been lost. The first signs of weight loss in the untreated dry sample and also redried sample were observed at approximately $280^{\circ} \mathrm{C}$. The first signs of weigth loss in the moisture saturated sample were observed at approximately $130^{\circ} \mathrm{C}$. Interestingly, the moisture saturated and redried sample exhibits a slightly greater total weight loss at $600^{\circ} \mathrm{C}$ than the untreated dry sample. This difference is possibly the result of the above-discussed decrease in crosslink density caused by the hydrolysis in the presence of an aggressive environment. A similar result has been reported in $\mathrm{Gr} / \mathrm{Ep}$ composites. ${ }^{38}$ However, in comparison with neat epoxy resin, the absolute difference in the total weight loss at $600^{\circ} \mathrm{C}$ between the moisture saturated and redried, on one hand, and the untreated dried $\mathrm{Gr} / \mathrm{Ep}$ composite, on the other hand, is much greater. ${ }^{38}$ 


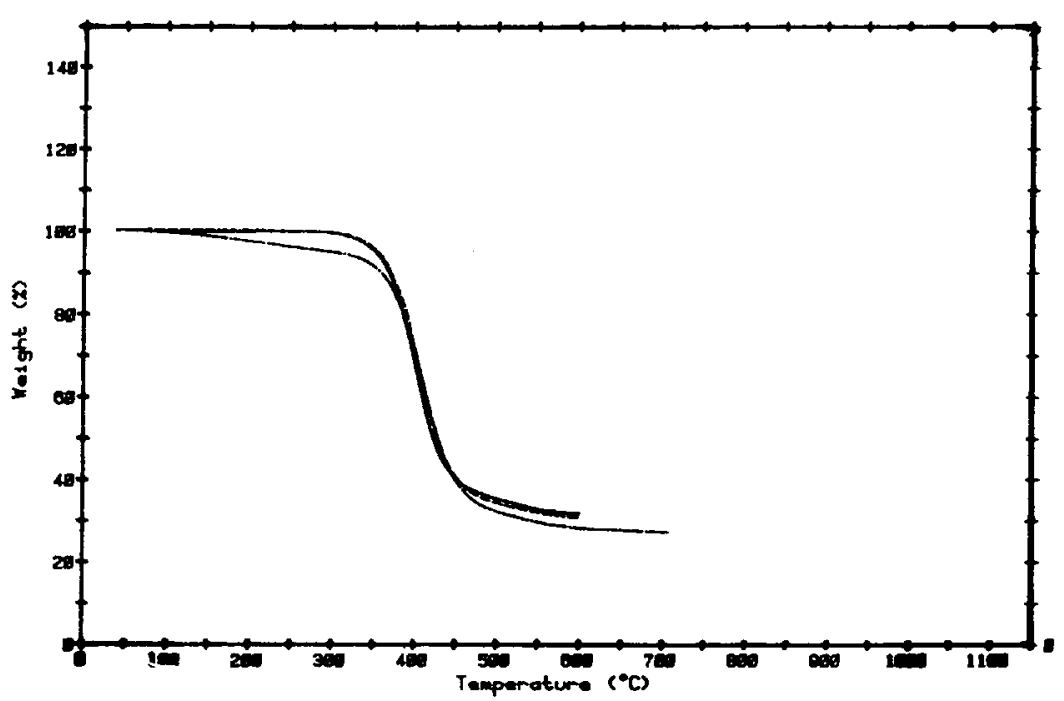

Fig. 13. TGA thermogram of weight loss as a fuction of temperature for: $(1,-)$ untreated, dry epoxy resin, $(2, \ldots+-)$ moisture saturated epoxy resin, and (3, . - ) moisture saturated and then dried epoxy resin.

That could be due to the fact that the resin network in the reinforcementmatrix boundary region (which exists only in the composite) experiences high residual strain and, as a result, undergoes more severe hydrolysis than the bulk epoxy resin in the aggressive environment.

TGA technique was also used to investigate the rate of moisture desorption from the saturated neat opoxy resin in the glass transition temperature range. Figure 14 shows a series of isothermal plots of weight change as a

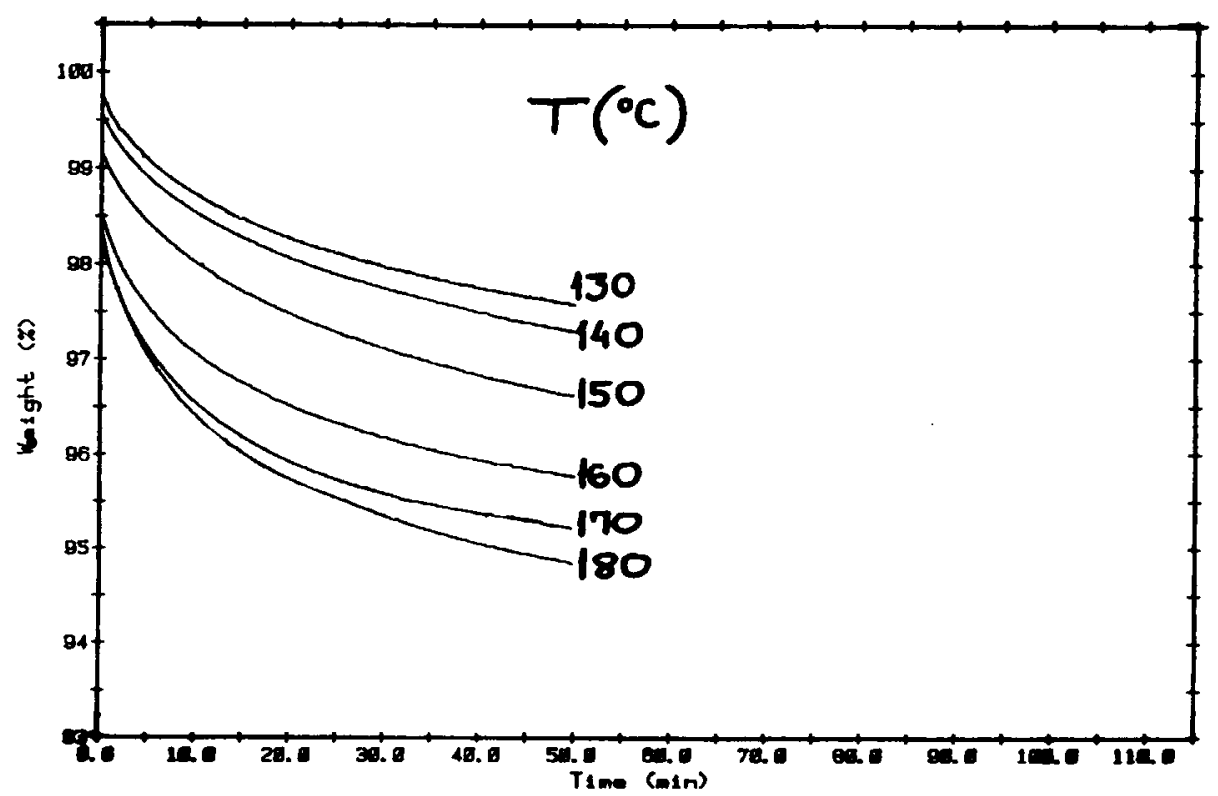

Fig. 14. TGA thermogram of weight loss of moisture saturated epoxy resin as a function of time with desorption temperature as a parameter. 
function of desorption time. It is clearly seen from this figure that the desorption rates at 130 and $140^{\circ} \mathrm{C}$ are relatively low and differ from each other only slightly. This temperature range $\left(130-140^{\circ} \mathrm{C}\right)$ is at the onset of the glass transition temperature range in the moisture-saturated sample (as described by the loss modulus trace in the dynamic mechanical spectrum, Fig. 8). As the temperature is increased to 150 and $160^{\circ} \mathrm{C}$, which is now within the glass transition range, the desorption rate increases significantly and appears to be very sensitive to the change in temperature from 150 to $160^{\circ} \mathrm{C}$. The increased desorption rate is likely due to the increased mobility of molecular chains, since a part of the resin, at those temperatures, has been transferred into rubbery state. As the temperature is increased further to 170 and $180^{\circ} \mathrm{C}$, which is now in the midst of the glass transition range, still higher desorption rates are observed. However, little difference is noted between 170 and $180^{\circ} \mathrm{C}$ due to the fact that the network is mostly in the rubbery state and hence the changes in chain mobility as a function of temperature $\left(T \geq T_{g}\right)$, as well as the moisture desorption rate, are not drastically influenced by temperature anymore.

\section{Thermal Spiking}

In order to simulate sudden changes in temperature experienced in actual service, the neat epoxy resin was thermally spiked at either 160 or $200^{\circ} \mathrm{C}$. The effect of spikes on the physical/mechanical properties of the resin was then evaluated. The primary goal of this part of our investigation was to assess the effect of thermal spikes executed at a temperature above the glass transition of the resin and at a temperature in the lower limit of the glass transition range. Consequently, spiking temperatures of 200 and $160^{\circ} \mathrm{C}$, respectively, were selected. We have recently reported a similar study of the effect of thermal spiking on the $\mathrm{Gr} / \mathrm{Ep}$ composite. ${ }^{38} \mathrm{~A}$ comparison of the effect of thermal spiking on the composite vs. the neat resin is certainly instructive. The first observation with the neat resin was that the thermally spiked (at either 160 or $200^{\circ} \mathrm{C}$ ) and then resaturated samples showed only a slight change in the moisture content and an insignificant change in the glass transition temperature. On the other hand, the glass transition temperature of the unidirectional (eight-ply) graphite/epoxy laminate decreased by about $10^{\circ} \mathrm{C}$ after one spike at $160^{\circ} \mathrm{C}$. Moreover, the composite glass transition temperature continued to decrease with the increased number of thermal spike cycles, as shown in Figure 15. This figure also shows that the moisture content of spiked samples increases noticeably with the number of spikes. We believe that, in composites, the thermal spikes primarily cause a relief in the restrictions to local molecular motions in the network, which are particularly pronounced within the reinforcement-matrix boundary region. ${ }^{38}$ As a result, microcracking is induced within this boundary region. Due to the mismatch in the thermal expansion coefficients between the epoxy matrix and the graphite fibers, the contractive force of epoxy matrix during quenching exceeds either the local cohesive force within the boundary region (some distance from the fiber surface) or the adhesive force along the fiber-matrix interface, in either case leading to the formation of microcracks. The latter facilitate additional absorption of mois- 


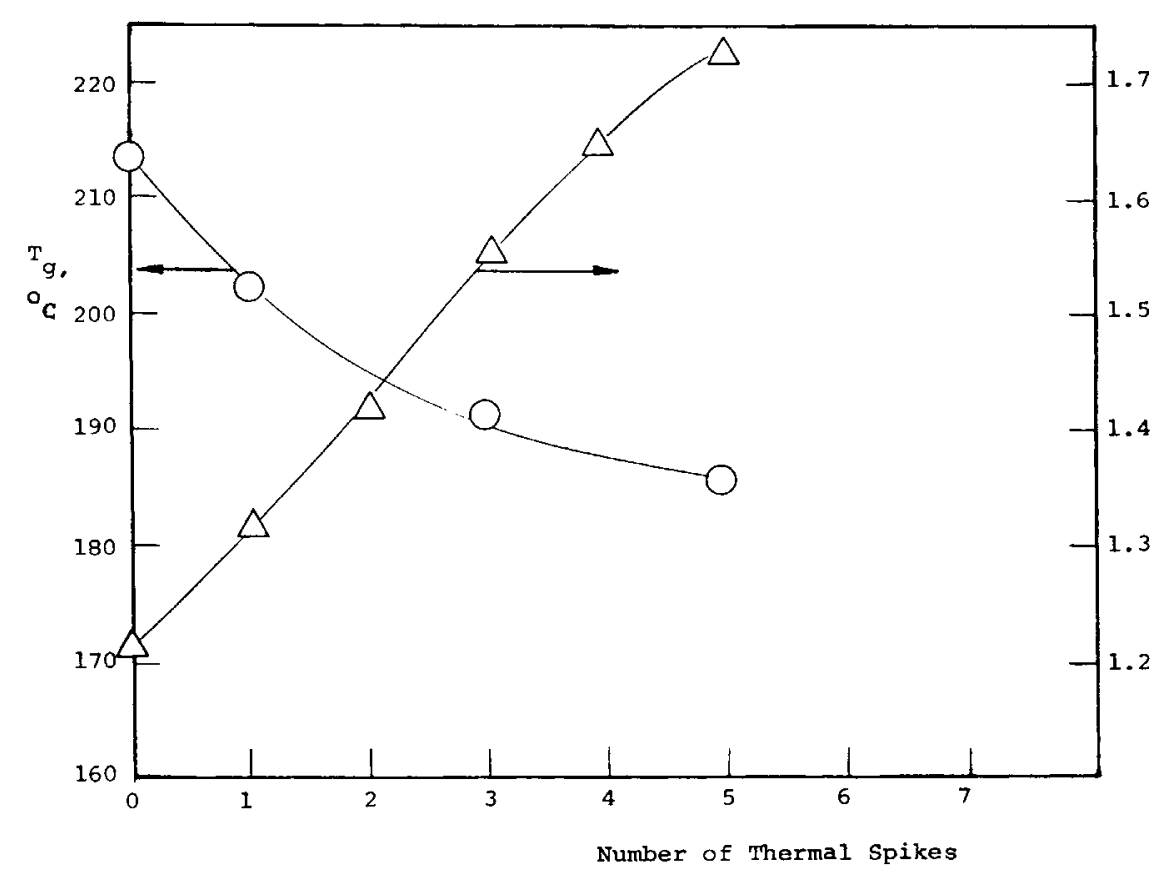

Fig. 15. Glass transition temperature and moisture content of the eight-ply undirectional AS/3502 graphite/epoxy composite as a function of number of thermal spike cycles at $160^{\circ} \mathrm{C}$.

ture into previously largely inaccessible regions of the network, and, as a result, the moisture content increases and the $T_{g}$ drops. Microcracking within the reinforcement-matrix boundary region has been corroborated by ample microscopic evidence..$^{39}$

Although the neat epoxy resin showed no apparent change in either the glass transition temperature or the moisture content after one spike (at either 160 or $200^{\circ} \mathrm{C}$ ) it shouldn't be $a$ priori concluded that no structural changes occurred during the spike. To obtain a closer look into possible changes in the microstructure of the spiked neat epoxy resin, a scanning electron microscopic investigation of fracture surfaces was conducted. Figure 16 shows the fracture surfaces of three samples: (a) a nonspiked untreated sample, (b) a sample spiked at $160^{\circ} \mathrm{C}$, and (c) a sample spiked at $200^{\circ} \mathrm{C}$. By comparing Figures $16(\mathrm{a})$ and $16(\mathrm{~b})$, one sees that the fracture surfaces of the nonspiked sample and the sample spiked at $160^{\circ} \mathrm{C}$ are quite similar, suggesting that the $160^{\circ} \mathrm{C}$ spike does not produce significant structural change on the microscopic level. In Figure 16(c), which shows a fracture surface of the sample spiked once but at $200^{\circ} \mathrm{C}$, one sees different morphology. This fracture surface is characterized by a considerable roughness and is obviously quite different from the other two. Since the roughness is not an artifact of the experimental technique, the $200^{\circ} \mathrm{C}$ spike has apparently produced changes in the neat resin on the morphological level which alter the pattern of the fracture surface. It is possible that thermal spiking at $200^{\circ} \mathrm{C}$ (temperature above the glass transition range of the moisture saturated epoxy resin) leads to the formation of microcracks in the specimens during quench. Browning ${ }^{40}$ found that microcracking in epoxy 

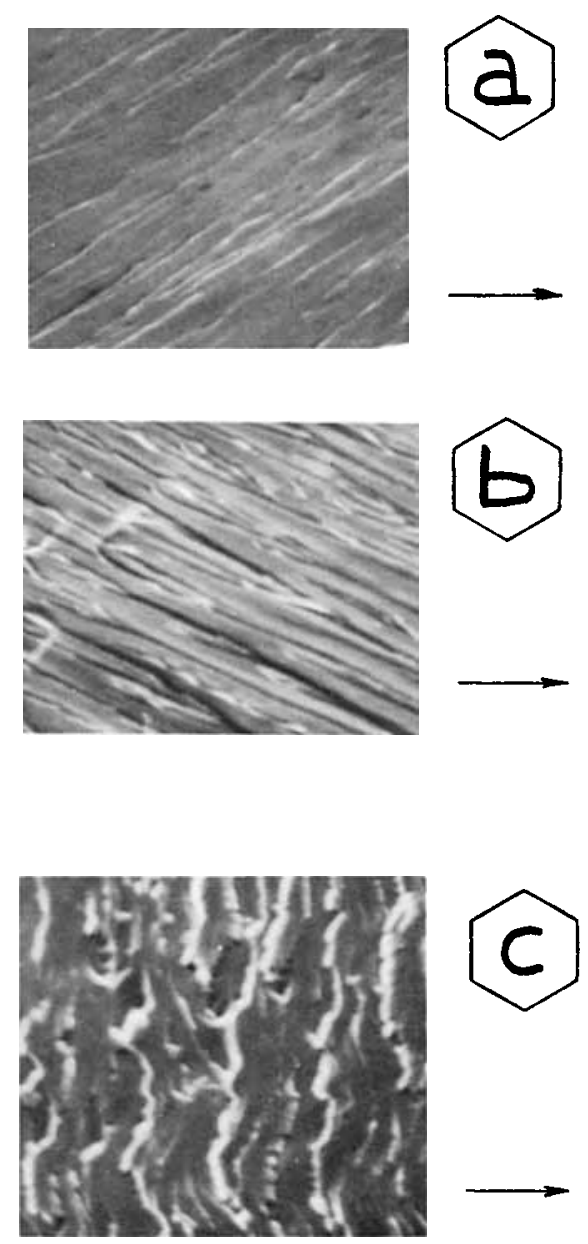

Fig. 16. Scanning electron micrographs of fracture surfaces of neat epoxy resins: (1) nonspiked untreated, (2) once-spiked at $160^{\circ} \mathrm{C}$, and (3) once spiked at $200^{\circ} \mathrm{C}$. Magnification $1,000 \times$. Arrows indicate fracture direction.

resins (such as Narmco 5208, Hercules 3501, and Fiberite 934) became apparent only when thermal spiking was done at temperatures higher than the wet glass transition temperature of the resin. But if microcracks form then why, in our study, no significant change in the moisture content was found after the samples were spiked at $200^{\circ} \mathrm{C}$ and resaturated with moisture? One possible explanation is that the induced microcracks must be very narrow. We also found that the specimens exposed to spike cycle at $200^{\circ} \mathrm{C}$ became very brittle, judged by a number of them that broke during the subsequent dynamic mechanical test. Narrow microcracks, like "zerothickness" cracks, are characterized by high stress concentration at both ends, which would account for the observed pronounced brittleness. At the present time, we are continuing an active electron microscopic investigation of fracture surfaces of thermally spiked samples. Further experimental evidence is needed to clarify the mechanism of microcracking in thermally spiked neat epoxy resins. 


\section{CONCLUSIONS}

A research study was conducted to investigate the effect of hygrothermal fatigue on physical/mechanical properties of the neat TGDDM/DDS epoxy resin and the graphite/epoxy composite. The mechanism of moisture diffusion in the neat resin on the morphological level was described and corroborated by dynamic mechanical and swelling strain measurements and electron microscopy. Moisture absorbed in the initial stage of diffusion preferentially enters the lower crosslink density matrix and strongly affects the $\beta$ transition, whereas moisture absorbed after a certain threshold value of moisture content swells the highly crosslinked structure and simultaneously decreases the glass transition temperature. The interactions between the resin network and the absorbed moisture were described in terms of the lubricity theory and the gel theory, two well-known molecular concepts of plasticization of amorphous polymers. The diffusion rate of moisture in and out of the neat epoxy resin was dependent on the mobility of molecular chains and temperature. After one cycle of moisture absorption and desorption, permanent changes in the physical/mechanical properties of neat epoxy resin were detected and were ascribed to a possible hydrolysis of the crosslinked network. In the thermal spiking experiment, only the specimens exposed to thermal spikes at temperatures above the glass transition of the moisture saturated epoxy resin underwent changes in their internal structure and contained microcracks. However, the increase in moisture content as a function of the number of thermal spikes was insignificant.

In comparison with the neat epoxy resin, the $\mathrm{Gr} / \mathrm{Ep}$ composite contains the reinforcement-matrix boundary region which is characterized by highest restrictions to molecular mobility. The absorbed moisture during the static hygrothermal fatigue cannot effectively plasticize that region. However, upon thermal spiking, the formation of microcracks within the reinforcement-matrix boundary region gives rise to additional absorption of moisture (unlike the neat resin) into previously largely inaccessible regions of the network.

This material is based upon work supported by the National Science Foundation under Grant No. MEA-8120211.

\section{References}

1. R. E. Mauri, F. W. Crossman, and W. J. Warren, ASMPE Symp., 23, 1201 (1978).

2. R. DeIasi and J. B. Whiteside, ASTM STP 658, Am. Soc. of Testing and Mater., Philadelphia, 1978, pp. 2-20.

3. J. M. Whitney and C. E. Browning, ASTM 658, Am. Soc. of Testing and Mater., Philadelphia, 1978, pp. 43-60.

4. S. Gazit, J. Appl. Polym. Sci., 22, 3547 (1978).

5. C. E. Browning, Ph.D. Thesis, University of Dayton, 1976.

6. E. L. McKague, J. D. Reynolds, Jr., and J. E. Halkias, J. Appl. Polym. Sci., 22, 1643 (1978).

7. T. S. Ellis and F. E. Karasz, Am. Chem. Soc., Org. Coatings, Appl. Polym. Sci. Proc., 48, 721 (1983).

8. F. Bueche, Physical Properties of Polymers, Interscience, New York, 1962.

9. P. R. Couchman and F. E. Karasz, Macromolecules, 11, 117 (1978). 
10. P. Peyser and W. D. Bascom, J. Mater. Sci., 16, 75 (1978).

11. P. Moy and F. E. Karasz, Polym. Eng. Sci., 20(4), 316 (1980).

12. C. E. Kumins and J. Roteman, J. Polym. Sci., A1, 527 (1963).

13. T. K. Kwei, J. Polym. Sci., A3, 3229 (1965).

14. T. Kajiyama, et al., J. Polym. Sci., Polym. Phys. Ed., 16, 1557 (1977).

15. J. Mijović and J. A. Koutsky, J. Appl. Polym. Sci., 23, 1037 (1979).

16. G. A. Pogany, Polymer, 11, 66 (1970).

17. F. R. Dammont and T. K. Kwei, J. Polym. Sci., A-2, 5, 761 (1967).

18. O. Delatycky, J. C. Show, and J. G. Williams, J. Polym. Sci., A-2, 7, 753 (1969).

19. K. M. Sinnott, Soc. Plast. Eng. Trans., 2, 65 (1962).

20. R. D. Andrews and T. J. Hammack, J. Polym. Sci. B, 3, 655 (1965).

21. J. G. Williams, J. Appl. Polym. Sci., 23, 3433 (1979).

22. T. Takahama and P. H. Geil, J. Polym. Sci., Polym. Phys. Ed., 20, 1979 (1982).

23. T. D. Chang, S. H. Carr, and J. O. Brittain, Polym. Eng. Sci., 22, 1205 (1982).

24. R. G. C. Arridge and J. H. Speake, Polymer, 13, 443 (1972).

25. J. D. Mijović and L. Tsay, Polymer, 22, 902 (1981).

26. M. Ochi, M. Okazaki, and M. Shimbo, J. Polym. Sci., Polym. Phys. Ed., 13, 443 (1972).

27. J. Mijović and J. A. Koutsky, Polymer, 20, 1079 (1979).

28. P. W. R. Beaumont and B. Harris, J. Mater. Sci., 7, 1965 (1972).

29. K. H. G. Ashbee and R. C. Wyatt, Proc. Roy. Soci. London, Ser. A, 312, 553-564 (1969).

30. D. H. Kaelble, P. J. Dynes, L. W. Crane, and L. Mans, J. Adhes., 7, 25 (1975).

31. H. Ishida and J. L. Koenig, Polym. Eng. Sci., 18(2), 128 (1978).

32. J. G. Williams, private communication.

33. A. K. Doolittle, in Plasticizer Technology, P. F. Bruins, Ed., Reinhold, New York, 1965, Vol. 1, Chap. 1.

34. F. W. Clark, Chem. Ind., 10, 225 (1941).

35. L. I. Nass, Encyclopedia of PVC, Dekker, New York, 1974, Vol. 1, Chap. 10.

36. R. M. Kessenikh et al., Vysokomol. Soyed, A14(2), 416 (1972).

37. G. Marom, Polym. Eng. Sci., 17, 799 (1977).

38. J. Mijović and K. F. Lin, in Polymer Blends and Composites in Multiphase Systems ACS Advances in Chemistry Series 206, Am. Chem. Soc., Washington, DC, 1984, pp. 332-366.

39. H. T. Hahn and R. Y. Kim, ASTM STP 658, Am. Soc. of Testing and Mater., Philadelphia, 1978, pp. 98-120.

40. C. E. Browning SAMPE 22nd National Symp. Exhibition, San Diego, CA, 1977, pp. 365394.

Received April 11, 1984

Accepted October 31, 1984 